\title{
UN ZACATE EMIGRANTE (TRICHOLAENA ROSEA NEES)
}

\section{Por el Ing. Gabriel Itié.}

Entre las Gramináceas que a través de los años han llegado a México y se han establecido definitivamente volviéndose subespontáneas, son más notables el Zacate guineo o privilegio (Panicum maximun Jacq) y el Zacate pará (Panicum purpurascens Raddle) formando ambos la base de la ganadería en las regiones cálidas. Otro emigrante, el Zacate Johnson (Sorghum halepensis (L) Pers), es temible por su agresividad, que anula sus buenas cualidades forrajeras. El Zacate Bermuda (Cynodon dactylon (L) Pers. ya muy esparcido por toda la República, es de carácter marcadamente ruderal y arvense.

A parte de las Gramináceas exóticas anteriores, que ocupan un lugar importante en ciertas formaciones vegetales, hay otra que ha pasado casi inadvertida hasta ahora, por ser aun bastnte escasa, pero que, al parecer, va ganando terreno, debido a ciertos caracteres que facilitan su migración. Se trata de la Tricholaena rosea Nees, Panícea designada habitualmente bajo el nombre de Zacate Natal en la literatura agrícola.

Es planta perenne, de corta vida, que forma mazos con tallos delgados que pueden alcanzar un metro de altura, más o menos tendidos en la base; vainas escasamente papillo-hirsutas; limbos angostos, planos, $5-15 \mathrm{~cm}$. de largo por 2 - $7 \mathrm{~mm}$. de ancho; panículas hermosamente sedosas, rosado purpúreas, de $10-15 \mathrm{~cm}$. de largo; espiguillas alrededor de $5 \mathrm{~mm}$. de largo.

Esta especie tiene cierto valor como forraje y puede utilizarse en los suelos arenosos pobres.

Hitchcock, en su obra "Gramináceas Mexicanas en el Herbario de los Estados Unidos" no menciona la Tricholaena rosea, lo que indica que hasta 1913 no había sido colectada y posiblemente no existía en México. Tampoco se encuentra señalada por el Prof. C. Conzatti ęn su "Flora Taxonómica Mexicana", aunque figura entre el material colectado en el Valle de Oaxaca por el Dr. Pavía e, indudablemente no existía en aquella región cuando colectaba el Prof. Conzatti, pues no hubiera escapado a la atención de tan avisado botónico. 
El primer ejemplar de Tricholaena rosea colectada parece ser el que figura en el Herbario Nacional. Corresponde al número 860 de la colección del Ing. Jesús González Ortega y lué recogido en Mazatlán, Sin. con fecha enero de 1932, atribuyendosele el nombre vulgar de zacate aceitunilla. En el herbario mencionado no figuran más ejemplares de dicha Gramínea. En el Herbario del Instituto de Investigación Agropecuaria, se encuentra el ejemplar ya mencionado como colectado en Oaxaca, por el Dr. Pavía.

El autor de esta nota ha encontrado Tricholaena rosea en las estaciones siguientes:

1.-El Potrero, Ver., sobre un montón de escombros, en la orilla derecha del río Atoyac, junto al ingenio.

2.-A ambos lados del Ferrocarril Mexicano de México a Veracruz, a unos cuantos kilómetros antes de Soledad Doblado.

3.-Valle de Tuxtla Gutiérrez, Chis., donde forma manchas esporádicas, y abunda especialmente en un campo abandonado, en las faldas del Cerro Hueco.

4.-A ambos lados de la Carretera Internacional que desde Chiapas de Corzo sube hacia Ixtapan. Esta estación, aparentemente reciente y en vía de progresión, puede considerarse como una extensión de la anterior, por su proximidad.

5.-Comitán, Chis., en un barbecho cercano a la ciudad.

6.-A ambos lados de la carretera de Coatzacoalcos a Minatitlán. Ver., entre los kilómetros 23 y 24 desde la primera ciudad.

7. -Talud en la carretera México Cuernavaca, a la entrada de esta última población. Es un ejemplar depauperado, procedente evidentemente de una invasión reciente, pues nunca se había observado la presencia de Tricholaena rosea en esta zona.

La distribución esporádica de las estaciones arriba mencionadas y la enorme distancia que las separa permite suponer que se trata de invasiones diferentes de Tricholaena rosea en el territorio mexicano, ignorándose la fecha de las mismas y su procedencia.

La presencia de esa especie a lo largo de las vías férreas y de las carreteras indica que las vías de comunicación son un camino de invasión de dicha Graminácea.

El hecho de que Hitchcock ni el Prof. Conzatti mencionen la presencia de Tricholaena rosea en México y de que sólo exista en el Herbario Nacional un ejemplar de la misma, colectado en 1923, indica que la introducción de esa especie en la República es relativamente reciente.

Debido a su agresividad y a la facilidad de su dispersión es probable que el área geográfica de la mencionada Graminácea en la República irá extendiéndose paulatinamente. 